\title{
Public Health in the Western States
}

\author{
By WILTON L. HALVERSON, M.D.
}

$\mathrm{P}$ UBLIC HEALTH services in the western States and Territories have developed remarkably since the organization of the Western Branch of the American Public Health Association 23 years ago.

The rapid increase of the population of the West and the resulting industrial expansion, accentuated by the production requirements of World War II and the present situation, have been accompanied by tremendous health, social, and economic problems, the solution of which is taxing our resources. It requires the best combined efforts of every individual who finds himself a part of the movement.

On the West was placed the responsibility of providing a tremendous amount of war materials, since the war requirements were far greater than the potential capacity of the eastern and midwestern production centers. The danger of overconcentration of industry in any section of the country was an additional and potent reason for the decentralization of the shipbuilding and airplane industry. The West offered labor reserves and natural resources that could not be ignored. California's war contracts, for example, were larger than those of any other State for about 2 years.

With the end of actual fighting and the fulfillment of war contracts, the expected largescale unemployment and an exodus of workers

Dr. Halverson, director of public health of the State of California, is president of the American Public Health Association. This article is based on a paper presented at the annual meeting of the Western Branch of the Association, Denver, Colo., June 1952.

Vol. 68, No. 3, March 1953 to their former homes in the Midwest and the South did not occur. On the contrary, the population increase continued almost unabated. Thousands of war veterans who had spent months in the training camps in the West decided to make the West their permanent home. And industry, quick to see the advantage of manufacturing commodities near the place of consumption, converted war plants to peacetime production.

The public health profession is particularly challenged not only by the problems posed by the physical characteristics of the area, such as the limited water resources in a large part of the West and the rapid industrialization of its centers, but also by the country's entrance into a new phase of scientific development, the atomic age. Atomic development comes at a period when time and space have been compressed by transportation of a speed surpassing sonic limits and a time in history when world peace is uncertain.

What part will the public health profession of the West play in such a time as this? Will we stay with the stereotyped and traditional aspects of our "basic six," or will we stir into an awareness of the problems confronting us now and think and plan for the eventualities of this year and the years to come?

There are many problems for which we must find solutions if we are to discharge the responsibilities society has placed upon us.

\section{Atomic Energy Confrol}

In atomic energy we have probably the most significant and potentially dangerous processes to which society has ever been exposed. Dr. 
Abel Wolman has pointed out: "In the place of a few radium dial painters doing standardized work ... thousands of workers now perform hundreds of tasks in the vicinity of materials releasing much more radiation than man has ever known before. . . . Some idea of this total rapid advance may be obtained from the fact that less than 10 years ago approximately 3 pounds of radium were under human control. Today radioactive materials are being produced and in many instances are being used to the equivalent of millions of pounds of radium" (1).

The interest and concern of the public health worker should not await the solution of all of the inherent problems. This may take a long time in such a complex field, and in the meantime hundreds of deaths may take place. Like any other problem, it requires analysis and action on the basis of the best available evidence. The epidemiologist, for example, will in this case be concerned with the amount, type, and period of radiation rather than with the types and virulence of bacterial infection. "The sanitary engineer must think about the number and size of processing units which require water supply, heat exchange, drainage, air conditioning, and ventilating equipment" (2).

Information regarding the distribution of radioisotopes, which has grown from a few hundred shipments in 1946 to several thousands annually, is made available to State health departments by the Atomic Energy Commission. The only information withheld from the States relates to shipments for classified uses.

The Atomic Energy Commission has been careful to supply the user with information regarding toxicity of the materials and the length of safe exposure. In spite of these precautions mistakes can be made and accidents may occur. In California a drum of radioactive cobalt accidentally fell from a truck. Fortunately, it was picked up by students who understood its significance and returned it to the laboratory. In another instance, a medical technician in a southern hospital was conducting analytical procedures with a radioactive substance in a manner which was subjecting her to total radiation of many times tolerance (1).

Are waters used for cooling properly protected from radiation or if exposed are they properly safeguarded? Are industrial wastes from establishments using these products properly controlled so as to prevent harmful contamination to people in the general area and to life in general? These are questions of prime importance to the public health.

While the information made available to the public has sometimes been overdramatized, the evidence available is sufficient to indicate the great importance of establishing control programs.

This is a field which requires careful exploration before administrative action is taken. California is in the process of this phase of the work. Following consultation with the Public Health Service, the State health department has assigned primary exploratory responsibility to an engineer who will, with the help of a staff advisory committee and other experts, outline a program of control which the department will recommend to the governor and the legislature for action.

Health departments, particularly in the more populous States, can no longer allow events to take their natural course in this urgent problem.

\section{Occupational Health}

With the rapid industrialization of the West, we must give greater consideration to, and develop a broader interest in, the health of the worker. Our industrial growth is not simply an increase in size. It also relates to the development of new substances and new processes, the toxicity and potential danger of which in many instances have not been defined.

Hundreds of new chemicals are being introduced to control agricultural and domestic pests. A knowledge of the toxicology of parathion, a powerful and effective insecticide-one of the so-called nerve poisons-is of great importance in the protection of workers both in the factory and in the field. New materials and new methods are coming with such regularity and rapidity that we can apply the simile which so aptly described the golden age of bacteriology-they come like corn popping in a pan. This is truly the age of chemistry and physics, just as the last half of the last century was the age of bacteriology.

At the last meeting of the California Conference of Local Health Officers and of the Cali- 
fornia State Board of Health, we discussed the control of the chemical, lindane, an insecticide that can pass directly from the solid to the gaseous state, the speed of this transfer depending on the temperature of the solid.

An enterprising and well-financed company has developed a business based on the distribution of thermogenerators for the dissemination of lindane or other pesticides in eating places and other closed areas where insects are a nuisance. The question of hazard through inhalation and food contamination immediately confronts us and requires that a decision be made as to whether this method of insect control shall be regulated or prohibited.

So many new occupational health hazards are being introduced that industrial hygiene workers can scarcely become familiar even with the names of the new substances. While we are greatly concerned about the specific occupational health problems that relate to the worker's environment, we are also concerned about his general health and to this end should be developing methods and procedures to make available the various established health services.

It is timely that we think of industrial health in terms of general health, particularly because of the developing interest in chronic diseases and the accumulating knowledge, small as it is at present, about what can be done to prevent chronic disease and to prevent to some degree the premature disabilities these conditions bring about.

Labor and industry are approachable in this matter, and in some instances they are ready to work with public health agencies in developing. programs which will conserve the already short labor supply and which can lighten the load of workmen's compensation by protecting the health of the worker through well-planned preventive programs.

\section{Chronic Disease Control}

Chronic disease control is a controversial subject in many ways. Can a measurable amount of disability be prevented by early diagnosis and preventive measures? Should health departments be concerned with personal health only as it relates to contagious disease and the special field of maternal and child health? Are multiphasic screening tests profitable and effective? 'These elementary questions and many others require practical answers.

The Commission on Chronic Illness, jointly sponsored by the American Hospital Association, the American Medical Association, the American Public Health Association, and the American Public Welfare Association, has stated: "The basic approach to chronic disease must be preventive. Otherwise, the problems created by chronic diseases will grow larger with time, and the hope of any substantial decline in their incidence and severity will be postponed many years" (3).

Weight control is a specific preventive measure related to chronic illness. Public health agencies, both voluntary and official, can unite with other community organizations in planning a program which, if effectively carried out, can add productive healthful years particularly to those above middle age. Several health departments have already initiated such programs and undoubtedly others will marshal their nutritionists, health educators, and other workers to take aggressive action in this area of chronic disease prevention, which lends itself to the mass as well as the individual approach.

Much has been written concerning the relationship of health departments with the private practitioner of medicine. As the years have gone on, most health departments have developed a working relationship with medical societies and with such specialized groups as pediatricians and obstetricians. These working relationships have contributed much to the success of preventive programs. They have convinced most physicians that the purpose of the health department is not to foist "socialized medicine" on the community but to unite with physicians and hospitals in bringing to the community the advantages of preventive services when this is feasible.

In the development of the preventive aspects of the control of chronic illness, this close working relationship is vital. State and local health departments have here a unique opportunity to bring before medical societies the newer developments related to prevention. When this has been done, progress has been made not only in attaining immediate objectives, but also in developing good working relationships in other parts of the public health program. 
Here too is an opportunity to develop the interest of a State or local health council. Here is an objective which challenges the interest of almost every family in the community, for a great many have had the problem of earing for a close relative who has spent months or years the living victim of a chronic illness which perchance might have been prevented. It is a problem which each year results in an ever-increasing financial burden to the home, the county, and the State. Public health workers share with the community and private practitioners of medicine the responsibility of finding ways and means to reduce this financial and social burden by the application of preventive measures as they become arailable.

\section{International Health}

In addition to the responsibility we owe to our community, our State, and our Nation, there is an international responsibility. The United States fully supports the program of the World Health Organization, a specialized agency of the United Nations created for the purpose of improving the health of the people of.all nations. And for 10 years we have participated in bilateral cooperative health programs in Latin America, administered by the Institute of Inter-American Affairs. Congress has subsequently adopted the policy of providing technical assistance, including health programs, in other underdeveloped countries. In addition to the 17 countries of Latin America, health missions have been established in $\mathrm{Li}$ beria, Greece, Turkey, Iran, India, and all of the countries of Southeast Asia. These bilateral programs are increasingly coordinated with the WHO programs (4).

From my own experience in surveying the health and sanitation program of the Institute of Inter-American Affairs, I am convinced that the public health movement in Latin America has been materially advanced and that there is tangible evidence of appreciation of the help that has been given.

I am also convinced that if the United States is to continue successfully the policy of technical assistance in the field of public health, ways and means must be found to use health personnel of State and local health departments, medical schools, public health schools, voluntary health organizations, private physicians, and all of the other health resources of the various States. Some plan must be developed which will make it possible for health workers to be released for periods of foreign service in order that the programs may be conducted effectively, with credit to the health profession and to our country.

Public health workers can no longer be content and satisfied to restrict their interests to traditional public health services in this country in the face of the crying needs of a world at the crossroads. We must indeed continue to carry on these programs and in addition we must accept the responsibility of developing new and needed programs at home and be willing on call to assist our world neighbors in taking their early steps in the development of health services.

\section{REFERENCES}

(1) Wolman, Abel: Public health aspects of atomic energy. Am. J. Pub. Health 40: 1502-1507 (1950).

(2) Gorman, A. E., and Wolman, Abel: Some public health problems in nuclear fission operations. Am. J. Pub. Health 39 : 443-453 (1949).

(3) Steps toward prevention of chronic disease. Summary of the National Con erence on Chronic Disease; Preventive aspects, held March 12-14. 1951. Raleigh, N. C., Health Publications Institute, 1951.

(4) Hyde, Henry van Zile: Bilateral international health programs of the United States. Am. J. Pub. Health 41: 1473-1476 (1951). 